\title{
LUCES Y SOMBRAS DE LA ESCUELA DE FRANKFURT. MATERIALIDAD NEGATIVA Y EXTERIORIDAD*
}

\author{
Luis Martínez Andrade \\ CriDIS/SMAG, Université catholique de Louvain \\ luisma_andrade@hotmail.com
}

\section{RESUMEN}

El proyecto intelectual de Max Horkheimer, conocido como Teoría critica, fue fundamental para develar las aporías e ilusiones de la modernidad capitalista. No hay duda de que las contribuciones de la Escuela de Frankfurt siguen siendo imprescindibles para una crítica de la dinámica destructora de la formación social hegemónica: racionalidad instrumental, industria cultural, agudización de los antagonismos sociales, autodestrucción del iluminismo, pedagogía del opresor, entre otros. Sin embargo, desde el giro descolonial, se pueden observar algunos límites en su crítica de la modernidad. El objetivo de este artículo es señalar algunas limitaciones geopolíticas de la Escuela de Frankfurt.

Palabras clave: Escuela de Frankfurt, teoría crítica, giro descolonial, exterioridad, Filosofía de la liberación.

\section{LIGHTS AND SHADOWS OF THE FRANKFURT SCHOOL. NEGATIVE MATERIALITY AND EXTERIORITY}

\section{Abstract}

Max Horkheimer's intellectual project, known as critical Theory, was crucial to revealing the contradictions and illusions of capitalist modernity. There is no doubt that the contributions from the Frankfurt School continue to be necessary for a critique of the destructive dynamic of the formation of social hegemony: instrumental rationality, cultural industry, a deepening of social antagonisms, the self-destruction of the Enlightenment, the pedagogy of oppression, amongst other things. However, since the decolonial turn, it is possible to observe some limits of its critique of modernity. The object of this article is to point out some geo-political limitations of the Frankfurt School.

Keywords: Frankfurt School, critical theory, decolonial turn, exteriority, Philosophy of Liberation. 


\section{MAX HORKHEIMER Y LOS ORÍGENES DE LA ESCUELA DE FRANKFURT}

El sociólogo franco-brasileño Michael Löwy sostiene que la visión romántica del mundo es un rasgo que caracteriza a algunos pensadores judios de Europa central (Mitteleuropa) de finales del siglo xIx y de principios del $\mathrm{xx}^{1}$. Para Löwy, el romanticismo no es sólo un movimiento literario o una corriente estética sino una Weltanschauung, es decir, «un estilo de pensamiento y una estructuración de actitudes y sentimientos, una Stimmung presente en el conjunto de los ámbitos de la vida cultural $»^{2}$. Dicho ethos romántico implica una crítica cultural de la civilización capitalista moderna en nombre de valores "premodernos» o "precapitalistas». En ese sentido, la visión romántica del mundo es una denuncia contra la cuantificación y la mecanización de la vida, la reificación de las relaciones sociales, la racionalidad instrumental (Zweckrationalität) y el espíritu calculador que configura la cultura moderna. Aunque existen tendencias conservadoras o reaccionarias del romanticismo (una visión paseista de la historia) también hay las revolucionarias y anticapitalistas (Ernst Bloch, Walter Benjamin o José Carlos Mariátegui, por mencionar algunas figuras) ${ }^{3}$.

Hijo de un acaudalado empresario y propietario de varias fábricas textiles en el distrito de Zuffenhausen, en Stuttgart, el filósofo Max Horkheimer (1895-1973) asistió a un Realgymnasium, institución que preparaba a los jóvenes para carreras prácticas, pues se esperaba que se hiciera cargo de los negocios familiares ${ }^{4}$. Posteriormente, con ayuda de su padre, Moritz Horkheimer, obtuvo una pasantía en las ciudades de Bruselas y de Manchester. En la capital de Bélgica, también llegó su amigo Friedrich Pollock (hijo del dueño de una fábrica en Friburgo de Brisgovia, Pollock obtuvo en 1923 el título de doctor por una tesis sobre la Teoría del valor-trabajo de Karl Marx. La amistad entre Max y «Fritz» empezó en 1911 y fue este último quien acercó a Max a la obra de Arthur Schopenhauer. Además, Pollock estuvo casado con una de las primas de Félix José Weil) $)^{5}$. Poco tiempo después, se une al grupo

* Este artículo tiene origen en la conferencia impartida el 30 de abril de 2021 en el marco de la Cátedra Cultural Javier Muguerza de la Universidad de La Laguna. El autor agradece la invitación y los comentarios de los profesores Vicente Hernández Pedrero, Roberto Rodríguez Guerra y Miguel Mandujano Estrada.

${ }^{1}$ Löwy, M. Rédemption et Utopie. Le judaïsme libertaire en Europe Centrale, Paris, Sandre, 2009. 2015, p. 39.

${ }^{2}$ Löwy, M. Judios heterodoxos. Romanticismo, mesianismo y utopia, Madrid, Anthropos,

${ }^{3}$ Löwy, M. y SAYre, R. Esprits de Feu. Figures du Romantisme anticapitaliste, Paris, Sandre, 2010.

4 Wiggershaus, R. La escuela de Fráncfort, México, FCE, 2011.

5 «Félix José Weil es, sin duda, el fundador del proyecto intelectual marxista más importante del siglo xx, mismo que a futuro sería conocido como la primera Escuela de Frankfurt; proyecto marxista que, ya instalado en los Estados Unidos, sería progresivamente modificado». García Corona, O. Una crítica descolonial de la Escuela de Frankfurt, Buenos Aires, Poliedro, 2021, p. 167. 
la prima de Max: Suze Neumeier ${ }^{6}$. Para el verano de 1914, el bateau ivre del trío ya estaba instalado en un pequeño apartamento en Londres. Cuando las familias Neumeier y Horkheimer se enteraron decidieron poner fin a esta «escandalosa» aventura. El padre de Suze, pistola en mano, se apersonó en la capital inglesa. A su regreso a Stuttgart, Max comenzó una relación con una mujer ocho años mayor que él: Rose Riekher. Secretaria particular de Moritz Horkheimer, Rose no sólo provenía de una familia modesta sino que además no era judía. Max y Rose se conocieron en una fiesta de navidad organizada por la empresa en diciembre de $1914^{7}$.

Durante los años que van a ahogar a Europa en un terrible bańo de sangre (1914-1918), Max Horkheimer no sólo experimenta una profunda crisis «religiosa» sino que además muestra un abierto rechazo a los valores de la sociedad liberal burguesa. De ese período datan sus primeras novelas cortas (L'isle heureuse, Leonhard Steirer, Spring, Aus der Pubertät, Trabajo, entre otras) y su interés tanto por la literatura expresionista como por el drama. Según el investigador Stuart Jeffries, en aquella época, a través de su producción literaria, Horkheimer expresó su rebelión ante las injusticias:

Es muy difícil no leer estos relatos como romans à clef. El atormentado hijo del industrial de Leonhard Steirer o el revolucionario de Trabajo son proyecciones del autor, y sus dramas se hacen eco de los problemas de Horkheimer con su padre en la vida real. Trabajo estaba dedicada a "Maidon», el cariñoso apodo que él daba a su entonces amante y futura esposa Rose Reikehr. Rose fue el amor de la vida de Horkheimer; la pareja se casó en 1926 y permanecieron juntos hasta la muerte de ella en 1969. Su negativa a abandonar a esta inadecuada mujer gentil de clase baja tipificaba la confrontación de Horkheimer con sus mayores, y en particular con su padre ${ }^{8}$.

Si bien Jeffries apunta algunos elementos de las «confrontaciones edípicas de los cultos y precoces judíos germanófobos de finales del siglo XIX y principios del XX»" (el caso de Leo Löwenthal, de Gershom Scholem y el mismo Max Horkheimer), también reconoce el acendrado rechazo al positivismo ${ }^{10}$ de buena parte de los

${ }^{6}$ La familia Neumeier solía pasar algunas temporadas en Stuttgart con los Horkheimer. Desde septiembre de 1912, Max y Suze desarrollaron un vínculo muy fuerte. Al final de su pasantía en Bruselas, en diciembre de 1913, Max regresó a Alemania. Su padre, Moritz, le informó que su siguiente parada sería Manchester. De camino a Inglaterra, Max se detuvo en la capital francesa para visitar a su prima. En la ciudad de Calais, Horkheimer le comenta a Pollock su deseo de estar con Suze. En una extensa misiva Max le expresa sus sentimientos, a lo que la joven Neumeier le responde, en una carta firmada con sangre, "Je suis à vous corps et âme» (Soy suya en cuerpo y alma). John Aвromeit, Max Horkheimer and the Foundations of the Frankfurt School, New York, Cambridge University Press, 2011, p. 26.

7 Ibidem, p. 31.

${ }^{8}$ Jefreries, S. Gran Hotel Abismo. Biografía coral de la Escuela de Frankfurt, Madrid, Turner, 2018, pp. 55-56.

\footnotetext{
9 Ibidem, p. 46.
}

${ }_{10}$ Ibidem, p. 162. 
futuros miembros del Instituto de Investigación Social (Ifs). Ahora bien, como sostiene Jean-Marc Durand-Gasselin, para comprender la «originalidad del proyecto de Horkheimer ${ }^{11}$, debemos tomar en consideración tanto el papel del filósofo marxista y crítico literario húngaro Georg Lukács (1885-1971) como el del austromarxismo (Max Adler, Rudolf Hilferding, Otto Bauer).

En el caso del autor de La teoría de la novela, Michael Löwy subraya la importancia que tuvieron las reuniones en Heidelberg bajo la férula del sociólogo alemán Max Weber. Formado por Georg Simmel ${ }^{12}$, Ferdinand Tönnies, Werner Sombart, Robert Michels, Ernst Troelsch, Ernst Bloch y Georg Lukács, el «círculo de Weber» mantuvo reuniones semanales de 1908 a 1918. Apoyándose en las memorias de uno de sus miembros, las del sociólogo Paul Honigsheim, Michael Löwy identifica no sólo una tendencia neorromántica ${ }^{13}$ sino también un marcado interés por la mística y la literatura rusa:

Empero, más que la Iglesia católica, fue la mística y la literatura rusa lo que lograba la unanimidad del círculo de Heidelberg, pues era una manera de rechazar la civilización occidental capitalista. Gracias a este eslavofilismo -estimulado por la participación en las reuniones dominicales (en casa de los Weber) de Nikolai von Bubnov, profesor de historia del misticismo en Heidelberg, autor de diversas publicaciones sobre la filosofía religiosa rusa en general y de Dostoyevski en particular, y por la presencia del escritor Fyodor Stepun, que introdujo al público alemán la obra del teórico del misticismo ruso Vladimir Soloviev- la obra de Tolstoi y de Dostoyevski estaba en el centro de las discusiones del círculo Max Weber, concretamente en el contexto de la contradicción entre la ética absoluta defendida por los escritores rusos (radical y sin cortapisas) y la ética de la responsabilidad [...]. Esta problemática obsesionaba todavía a Max Weber en 1919: en su famoso discurso dirigido a los estudiantes sobre la política como vocación, mencionó explícitamente al Gran Inquisidor de Dostoyevski como la expresión la más llamativa de esta contradicción ${ }^{14}$.

Hijo de un rico banquero judío de Budapest, Georg Lukács estuvo interesado por el romanticismo y, entre 1907 y 1908, se propuso redactar una obra que

${ }^{11}$ Durand-Gasselin, J.J. L'École de Francfort, Paris, Gallimard, 2012, p. 17.

12 Sobre la línea de continuidad entre el pensamiento de Georg Simmel y la Escuela de Frankfurt sobre la «tragedia de la cultura moderna», véase Gutiérrez Gutiérrez, E. «George Simmel: Una Teoría crítica de la cultura», Revista Laguna, 47, 2020, pp. 63-88.

${ }_{13} \mathrm{Al}$ respecto, Paul Honigsheim menciona que «Antes de la guerra, existía en muchos ambientes una tendencia a alejarse del modo de vida burgués, la cultura de la ciudad, la racionalidad instrumental, la cuantificación, la especialización científica y otras cosas consideradas odiosas [...] Lukács y Bloch, Ehrenberg y Rosenzweig fueron partisanos de esa tendencia. Este neo-romanticismo, por llamarlo de alguna manera, estuvo ligado al primer romanticismo por numerosos canales [...] El neo-romanticismo, bajos sus diversas formas, estaba representado en Heidelberg... y aquellos que se identificaban con él sabían a qué puerta dirigirse: la de Max Weber». Citado en Löwy, M. Pour une sociologie des intellectuels révolutionnaires. L'évolution politique de Lukacs 1909-1929, Paris, PUF, 1976, p. 45.

14 Ibidem, p. 46. 
llevaría por título El Romanticismo del siglo XIX. En 1911, publicó su libro El Alma y las formas, que estaba compuesto por ensayos sobre escritores vinculados al romanticismo: Novalis, Theodor Storm, Stefan Georg o Paul Ernst ${ }^{15}$. Durante su estancia en Heidelberg (1910-1915) no sólo estableció vínculos de amistad con el filósofo marxista Ernst Bloch sino que se relacionó con pensadores de la talla de Max Scheler, Karl Jaspers y Friedrich Gundolf. De hecho, el filósofo Nicolas Tertulian reconoce una continuidad entre el «escatologismo» (fórmula empleada por Weber) del joven Lukács y su metafísica del "género humano para sí» esbozada en su Ontología del ser social ${ }^{16}$. Sin embargo, a raíz de la Primera Guerra Mundial y del apoyo de Max Weber al imperialismo alemán, el joven antimilitarista Lukács decidió abandonar el círculo de Heidelberg. Según Michael Löwy el sentido político, anticapitalista y antimilitarista -tanto de E. Bloch como de G. Lukács- es otra expresión de esa visión romántica del mundo.

Por otro lado, la revolución bolchevique de 1917 tuvo un gran impacto en Lukács. Aunque el acercamiento de Lukács al marxismo fue provocado por sus lecturas de Dostoyevski y de Georges Sorel principalmente, durante el año de 1918 su mesianismo adquiere una tonalidad más política y revolucionaria. En diciembre de 1918, el autor de El Alma y las formas publicó un texto titulado «El bolchevismo como problema moral», en el que presentaba al proletariado como el portador de la redención social de la humanidad y como la clase social-Mesías de la historia del mundo. Un poco de tiempo más tarde, Lukács ingresó en el Partido Comunista Húngaro y, durante la República húngara de los Consejos, se convirtió en el comisario del pueblo de educación y cultura ${ }^{17}$. Dentro de los elementos que podemos destacar del «legado de Lukács»" ${ }^{18}$ se encuentran un renovado interés por Hegel, la noción de reificación y, por supuesto, las reflexiones en torno a la estética. Estas temáticas serán parte de las discusiones y preocupación intelectuales de los miembros de la Escuela de Frankfurt. Pero, sin duda alguna, es con su libro de 1923 Geschiste und Klassenbewusstein (Historia y consciencia de clase), publicado por la editorial berlinesa Malik-Verlag ${ }^{19}$, con el que Georg Lukács revolucionó la teoría marxista y, a su vez, marcó el espíritu del Instituto de Investigación social (Ifs).

Sobre el papel del austromarxismo es importante mencionar su contribución al socialismo en lo que respecta la perspectiva interdisciplinaria, la preocupación epistemológica (principalmente el pensamiento de $\mathrm{Kant}^{20}$ ), la atención a la historia social y a la economía política. Formado en torno a la asociación vienesa Zukunft, en la que participaban Rudolf Hilferding, Max Adler, Gustav Eckstein y

15 Löwy, M. Judios heterodoxos cit., p. 78.

16 Tertulian, N. Pourquoi Lukács?, Paris, FMSH, 2016, p. 241.

17 Löwy, M. Judios heterodoxos cit., p. 87.

${ }_{18}$ Durand-Gasselin, J.J. L'École de Francfort cit., 25.

${ }_{19}$ Casa editorial que contó con el apoyo financiero y material de Félix José Weil. Rolf Wiggershaus, La escuela de Fráncfort cit, p. 24.

${ }^{20}$ Max Horkheimer defendió su tesis de habilitación en 1925 sobre la teoría del juicio en Kant. Dicho trabajo fue asesorado por Hans Cornelius, filósofo neokantiano. 
Karl Renner, el austromarxismo se desmarcó de los socialistas alemanes a través de la publicación de la colección Marx Studien en 1904 y de la revista Der Kampf en 1907. Ciñéndose en una dinámica de «regreso a Kant», Max Adler y Otto Bauer confrontaron el pensamiento de Marx con los fundamentos epistemológicos y éticos de Kant. De hecho, Hilferding, Bauer, Adler y Henryk Grossman ${ }^{21}$ fueron alumnos del filósofo marxista y primer director del Instituto de Investigación social: Carl Grünberg (1861-1940). Sobre la inauguración, el 22 junio de 1924, del Instituto ubicado en la Viktoria Allee 17 en la ciudad de Frankfurt, Stuart Jeffries narra que

El ministerio de Educación había propuesto bautizarlos Instituto de Investigación Social Felix Weil, pero Weil declinó modestamente. La idea original de llamarlo Institut für Marxismus (Instituto de Marxismo) fue descartada por demasiada provocadora. De modo que dio en llamarse Institut für Socialforschung (Instituto de Investigación Social), y Weil invitó a Carl Grünberg a ser su primer director. Grünberg no fue su primera opción: inicialmente Weil se había acercado a un economista socialista llamado Kurtz Gerlach, pero este murió de un infarto a sus treinta y seis años, en 1922. Grünberg era profesor de derecho y ciencias políticas en la universidad de Viena con una reputación considerable como estudioso de la historia del socialismo y el movimiento obrero, y conocido principalmente por una revista académica titulada Grünbergs Arkiv ${ }^{22}$. Los primeros temas de investigación de Grünberg fueron los sindicatos internacionales, las huelgas, los sabotajes, la revolución como movimiento salarial, el antisemitismo como problema sociológico, la relación entre bolchevismo y el marxismo, el partido y las masas, los estándares de vida de la población, la mejora de Alemania ${ }^{23}$.

Observamos pues un interés por estudiar el desarrollo de las luchas del proletariado. En ese sentido, no podemos soslayar la importancia de la «Primera Semana Marxista del Trabajo», organizada en mayo de 1923 en el pequeño poblado de Geraberg en Turingia, ya que ésta tenía como objetivo comprender el fracaso de la revolución alemana de 1918-1919 y la implementación del socialismo. Promovido por Félix José Weil, dicho evento puede ser considerado como la semilla del Instituto de Investigación Social. Algunos de sus participantes provenían de la órbita del recién formado Partido Comunista Alemán: Konstantin Zetkin (hijo de Klara Zetkin),

${ }^{21}$ Originario de la ciudad de Cracovia, H. Grossman (1881-1950) fue un economista e historiador marxista que desde su juventud participó en actividades clandestinas ligadas al Partido Socialdemócrata Judio. Compañero de armas de Ludwig Wittgestein en el frente oriental del ejército austriaco, Grossman desarrolló una teoría económica de inspiración leninista sobre la muerte del capitalismo plasmada en su obra de 1929 La Ley de la acumulación y del derrumbe del sistema capitalista. A diferencia de los demás miembros del Ifs estableció vínculos orgánicos con sindicatos, organizaciones revolucionarias y partidos de izquierda. Kunn, R. Henrik Grossman and the Recovery of Marxism, University of Illinois Press, 2007.

22 Fundada en 1910, les Archiv für die Geschichte des Socialismus und der Arbeiterbewegung fueron una plataforma importante para difundir algunos textos de G. Lukács y del autor de Marxismo y Filosofía, Karl Korsch.

23 Jeffries, S. Gran Hotel Abismo cit., p. 91. 
Paul y Hedda Massing, Julian Gumperz ${ }^{24}$, Richard Sorge, entre otros. Aunque Karl Korsch y Georg Lukács, leninistas convencidos, participaron en las discusiones, sus caminos tomaron un derrotero distinto al de los futuros miembros del Ifs. La empresa de investigación no política promovida por la Ifs traicionaba, según ellos, la unidad entre teoría y práctica propia del marxismo ${ }^{25}$. Incluso, ańos más tarde, el autor de Historia y consciencia de clase criticaría el distanciamiento de la práctica política y el modo de vida burgués de los integrantes de la Escuela de Frankfurt ${ }^{26}$. Basándose en los recuerdos de Friedrich Pollock, el historiador Martin Jay sostiene que el Ifs fue concebido también en conversaciones «en el jardín de un castillo ubicado en el pueblo montańoso de Kronberg, en la cordillera del Taunus en 1922» con una persona que no participó en la «Primera Semana Marxista»: Max Horkheimer ${ }^{27}$.

\section{DE LA TEORÍA CRÍTICA AL GIRO CONSERVADOR DE LA ESCUELA DE FRANKFURT}

La denominación de «Escuela de Frankfurt» es una invención que comenzó a circular a partir de la década de los cincuenta y, por consiguiente, es posterior al regreso del exilio de algunos de sus miembros que se encontraban en el otro lado del Atlántico. Además, debemos señalar que, paradójicamente, es la producción de los ańos veinte y treinta, soslayada en los cincuenta, la que es frecuentemente referida para indicar su «identidad intelectual $»^{28}$. Por otra parte, es interesante mencionar que cuando dicha denominación empezó a ser utilizada, los planteamientos de M. Horkheimer y de T. Adorno ya habían tomado un cariz conservador ${ }^{29}$. Al respecto, S. Jeffries es categórico al sugerir que «en la obra Dialéctica de la Ilustración se destacaba el abandono por parte de la Escuela de Frankfurt de su anterior compromiso con el marxismo, así como su presente desesperación» ${ }^{30}$.

El ambiente político y cultural de la década de los veinte de la ciudad de Frankfurt es esencial para entender la fundación del Ifs. Recordemos que esta ciudad contaba una floreciente comunidad judía (alrededor de 30000 miembros) y allí

${ }^{24}$ Sociólogo estadounidense con estudios en Alemania, donde fue colega de Pollock y de Horkheimer. Durante la década de los treinta, Gumperz negoció con la Universidad de Columbia la posibilidad de acoger en Nueva York a la exiliada Escuela de Frankfurt. Jefreres, S. Gran Hotel Abismo cit., p. 222.

${ }_{25}$ JaY, M. Campos de fuerza. Entre la historia intelectual y la critica cultura, Buenos Aires, Paidós, 2003, p. 49.

26 García Corona, O. Una crítica descolonial de la Escuela de Frankfurt cit., p. 138. La crítica de Lukács se publicó en el prefacio de 1962 para la segunda edición de su Teoría de la novela.

27 JAY, M. «Ungrounded: el fundamento de la crítica o la crítica del fundamento. Horkheimer y los orígenes de la Escuela de Frankfurt», en S. Gandler (ed.), Teoría Crítica: imposible resignarse. México, MAPorrúa, 2016, p. 22.

${ }_{28}$ Durand-Gasselin, J.J. L'École de Francfort cit., 6.

${ }^{29}$ García Corona, O. Una critica descolonial de la Escuela de Frankfurt cit., p. 216.

30 Jefrries, S. Gran Hotel Abismo cit., p. 266. 
se había creado el famoso Freie Jüdische Lehrhaurs (Centro de enseñanza judío para adultos), clave para el Renacimiento Judio, en torno a la figura del rabino Nehemiah Nobel y en el que participaron personajes como Franz Rosenzweig, Martin Buber y Ernst Simon ${ }^{31}$. Con una tradición de menos subordinación a los gobiernos centrales, la burguesía de la ciudad, especialmente su parte judía, promovió la creación de su universidad y la fundación del Ifs. Esta última, al ser una institución académica privada, estaba exenta de aplicar las leyes antisemitas de la República de Weimar $\mathrm{y}$, por tanto, los docentes judíos podían impartir clases e investigar ${ }^{32}$. Igualmente, desde 1856, circulaba el diario más prestigioso de la época de Weimar: el Frankfurter Geschäftsbericht. Creado con la ayuda del banquero Leopold Sonnemann, este diario, a la postre, adopta el nombre de Frankfurter Zeitung y llega a convertirse en una especie de plataforma para las ideas del liberalismo de izquierda. Dentro de sus plumas más destacadas se encontraba la del crítico literario y fundador de la "teoría de la superficie»: Siegfried Kracauer ${ }^{33}$.

Es un hecho conocido que, en enero de 1928, Carl Grünberg fue víctima de un ataque de apoplejía y, por consiguiente, dejó la dirección del Ifs. Tres años más tarde, y después del interinato de F. Pollock, Horkheimer asume el cargo de director y con una disertación titulada «La actual posición de la filosofía social y las tareas a las que se enfrenta el Instituto de Investigación social» marcó «una ruptura con la trayectoria intelectual del Instituto bajo Grünberg » ${ }^{34}$ al sostener que era crucial «la conexión entre la vida económica de la sociedad, el desarrollo psicológico de los individuos y los desafíos en el campo de la cultura en su sentido más estricto» ${ }^{35}$. Aunque, a principios de los años treinta, Horkheimer ya había publicado su Dämmerung (Ocaso), una serie de aforismos redactados entre 1926 y 1931 y su texto «Los comienzos de la filosofía burguesa de la Historia»", es con su ensayo de 1937 «Teoría tradicional y teoría crítica ${ }^{37}$ donde coloca las bases de su proyecto intelectual: el método crítico-explicativo articulado a la supresión de la injusticia social. Efectivamente, en "Teoría tradicional y teoría crítica», Horkheimer hace hincapié en la manera en que el científico está sujeto al aparato social y, en ese sentido, reconoce la función social real de la ciencia. Del mismo modo, el creador del término Teoría 2009 , p. 10

${ }^{31}$ JAY, M. Campos de fuerza cit., p. 34

32 Gandler, S. Fragmentos de Frankfurt. Ensayos sobre la teoría crítica, México, Siglo XXI,

33 Traverso, E. Siegfried Kracauer. Itinéraire d'un intellectuel nomade, Paris, La découverte, 2006, p. 103.

${ }^{34}$ Durand-Gasselin, J.J. L'École de Francfort cit., 49.

35 Jefrries, S. Gran Hotel Abismo cit., p. 159.

36 «Por eso la voluntad de justicia (en el sentido de igualdad social, es decir, para superar los mencionados antagonismos) tiene que constituir uno de los contenidos de consciencia comunes a todas las épocas hasta nuestros días. La exigencia de justicia, en tanto que abolición de privilegios e instauración de la igualdad, proviene de las capas sociales inferiores, sometidas a la dominación». Horkheimer, M. Historia, Metafísica y Escepticismo, Madrid, Alianza, 1982, p. 41.

37 Dicho ensayo fue publicado por primera vez en la Zeitschrift für Socialforschung (Revista de investigación social) cuando Horkheimer ya se encontraba en los Estados Unidos de Norteamérica. 
crítica (Kritische Theorie) subraya la importancia de la denuncia de las estructuras de opresión y, al respecto, menciona que «la teoría esbozada por el pensar crítico no obra al servicio de una realidad ya existente: solo expresa su secreto ${ }^{38}$.

Para Horkheimer no era suficiente con reconocer el carácter antagónico de las relaciones sociales objetivamente existentes, sino que además era fundamental que la Teoría crítica se convirtiera en fuerza real. Sin omitir la forma contradictoria de la actividad humana en la época moderna, la teoría crítica asume la necesidad de suprimir la oposición entre la conciencia de fines, la espontaneidad y la racionalidad configuradas tanto en el individuo como en las relaciones del proceso de trabajo.

Pero el comportamiento conscientemente crítico es inherente al desarrollo de la sociedad. La construcción del acontecer histórico como el producto necesario de un mecanismo económico contiene, al mismo tiempo, la protesta contra ese orden, originada justamente en ese mecanismo, y la idea de la autodeterminación del género humano, es decir, la idea de un estado tal que, en él, las acciones de los hombres ya no emanen de un mecanismo, sino de sus mismas decisiones. El juicio acerca de la necesidad del acontecer, tal como este último se ha dado hasta ahora, implica aquí la lucha por transformar una necesidad ciega en otra plena de sentido. Pensar el objeto de la teoría como separado de ella falsea la imagen y conduce a un quietismo o conformismo. Cada parte de la teoría supone la crítica y la lucha contra lo establecido, dentro de la línea trazada por ella misma ${ }^{39}$.

A diferencia de las conservadoras posiciones positivistas o de las conformistas perspectivas derivadas del empirismo, la Teoría crítica no se amparó en una falsa neutralidad axiológica, sino que tomó posición y, por tanto, asumió un papel transformador. La Teoría crítica denunció la función ideológica de las corrientes teóricas que naturalizan los mecanismos de dominación y explotación. Frente a una teoría tradicional que justificaba la injusticia social y que además era indiferente al sufrimiento de las víctimas, la Teoría crítica operó un giro material («materialidad» en el sentido de corporalidad viviente $)^{40}$ con serias consecuencias ético-políticas.

En su obra Una crítica descolonial de la Escuela de Frankfurt, el filósofo Omar García Corona propone la noción de «giro material» para dar cuenta de tres «determinaciones orgánicas» que componen el «modelo» de la Teoría crítica: 1) Materialidad como corporalidad viviente (como consecuencia de la concepción humana en la antropología semita y de la fenomenología de Edmund Husserl); 2) Materialidad como el acontecer histórico-social (fruto del empleo del método dialéctico de Marx); y 3) Materialidad como producción no neutral del conocimiento (en donde el proceso científico es visto como proceso social y, además, se privilegia el hecho de iluminar las regiones ocultas de la realidad ${ }^{41}$. Siguiendo algunos planteamien-

38 Horkheimer, M. Teoría crítica, Buenos Aires, Amorrortu, 1974, p. 248.

39 Ibidem, p. 259.

40 Dussel, E. Ethics of Liberation. In the Age of Globalization and Exclusion, Duke University Press, 2013, pp. 55-107.

${ }^{41}$ García Corona, O. Una critica descolonial de la Escuela de Frankfurt cit., p. 40. 
tos del filósofo Enrique Dussel, García Corona aduce la importancia tanto del «giro material» como del "momento negativo» de la Teoría crítica en la superación de la impronta de la metafísica occidental y su corolario: la crítica de sus concepciones estáticas y universalistas del ser humano, la historia y el conocimiento.

Aunque muchos estudiosos de la historia de la Escuela de Frankfurt han apuntado el giro conservador, consecuencia de su exilio en el otro lado del Atlántico, de M. Horkheimer y de T. Adorno, García Corona, por su parte, aborda el eurocentrismo y la colonialidad del poder/saber en las reflexiones del creador del término Teoría crítica en lo referente a las poblaciones indígenas. Para Horkheimer los pueblos originarios no experimentan del mismo modo la "percepción de la identidad", ni tampoco cuentan con la capacidad para «hacer frente a las contingencias del mañana $»^{42}$. En otras palabras, y siguiendo la estela hegeliana, las poblaciones indígenas (y negras) son consideradas como representantes de la «minoría de edad de la humanidad». Además, es importante mencionar que otro elemento que le permite a Horkheimer denostar a los pueblos originarios radica en la noción de propiedad heredada. Paradójicamente, con la referencia a dicha noción de propiedad, el autor de Dämmerung estaba siguiendo la misma línea de argumentación aristotélica del autor de De justis belli causis apud indios (1550), el sacerdote español Juan Ginés de Sepúlveda (1490-1573), cuando sostenía que la guerra de Conquista en América era justa ${ }^{43}$. Más sensible al sufrimiento de las poblaciones indígenas fue Walter Benjamin cuando señaló que «la historia colonial de los pueblos europeos comienza por el monstruoso proceso de la Conquista de América que convierte al Nuevo Mundo en una sala de torturas» ${ }^{44}$. Huelga decir que, para el autor de las Tesis sobre el concepto de historia, Ginés de Sepúlveda representaba al teórico de la razón de Estado (Der Theoretiker der Staatsraison $)^{45}$.

Por otra parte, el desprecio de Adorno hacia el jazz es otro elemento que ha sido analizado tanto por Stuart Jeffries como por García Corona en sus respectivas investigaciones dedicadas a la Escuela de Frankfurt. Efectivamente, para el autor de la Dialéctica Negativa, los supuestos «elementos progresistas» del jazz eran un simple envoltorio que ocultaba «algo profundamente reaccionario" $y$, en ese sentido, reforzaba las cadenas de la dominación ${ }^{46}$. Publicado en 1936 y firmado con el seudónimo de Hektor Rottweiler, «Sobre el jazz» es el primer texto en el que Adorno sugiere que este estilo musical es una manifestación de la mercantilización del arte bajo el capitalismo. Lejos de ser portador de un potencial revolucionario, para Adorno el jazz es simple y llanamente un reflejo «sadomasoquista» de la sociedad burguesa.

42 Citado en García Corona, O. Una crítica descolonial de la Escuela de Frankfurt cit., p. 89.

43 Wallerstein, I. Universalismo europeo. El discurso del poder, México, Siglo XXI, 2007.

44 Benjamin, W. Romanticisme et critique de la civilisation, Paris, Payot, 2010, p. 129.

45 Sobre un análisis de la «dialéctica moral del catolicismo» -para emplear el término de M. Löwy- en Walter Benjamin, véase Löwy, M. Cristianismo de liberación. Perspectivas marxistas y ecosocialistas, Barcelona, El Viejo Topo, 2019.

46 Traverso, E. La pensée dispersée. Figures de l'exil judéo-allemand, Paris, Lignes, 2004, p. 116. 
Castración simbólica, orgasmo prematuro e incompleto, este género musical era, para el autor de Teoría estética, también un producto mercantil.

Si bien el giro conservador de Adorno y de Horkheimer se puede rastrear desde su exilio en los Estados Unidos, cuando se tomaban el privilegio de censurar algunos textos de Walter Benjamin (por ejemplo, en «Eduard Fuchs, coleccionista e historiador", en el que el término fascismo se convertía en "doctrina totalitaria» o el de "comunismo» se transformaba en "fuerzas constructoras de la humanidad»), la posición más reaccionaria de sus posturas es evidente a finales de la década de los sesenta. Mientras que el primero, hostil al movimiento estudiantil alemán, llama a las fuerzas del orden para intervenir en la universidad, el segundo justifica la guerra de Vietnam. Creemos que no le falta razón a Enzo Traverso cuando menciona que una diferencia entre el marxismo estético de Adorno y el mesianismo revolucionario de Benjamin radica en el papel de la lucha de clases. Mientras que, para el autor de las Tesis sobre el concepto de la historia, «el sujeto del conocimiento histórico es la clase oprimida misma, cuando combate ${ }^{47}$; para el autor de Minima Moralia toda referencia al proletariado es causa de suspicacia y, por tanto, rechaza cualquier hipótesis de compromiso político. Así, nos dice Traverso, «Adorno siempre permanece impenetrable a toda tentación de otorgar una traducción política a su teoría crítica $»^{48}$. Si para el historiador italiano, la imposible traducción política de la propuesta estética de Adorno es crucial para entender su giro conservador, García Corona identifica los atavismos eurocéntricos de los autores de la Dialéctica del iluminismo. Al respecto, sostiene que

El problema para la Teoría crítica es que llega a un punto en que sus análisis sociales no pueden liberarse de una epistemología que termina por mostrar que su discurso se mueve al interior de una lógica moderna que reduce el horizonte de posibilidades a la disyuntiva colonialista: civilización o barbarie, con todo y las consecuencias que de ello se derivan. El tema de Adorno y el jazz, por su nivel de radicalidad, es sin duda el mejor ejemplo; la explicita violencia racista, epistemológica y cultural contra la negritud y sus expresiones musicales, calificada como 'barbarie' y pretendidamente justificada desde un ethos eurocéntrico-colonial supremacista es grotesco. En el caso de Horkheimer, respecto a su concepción antropológica moderna, al referirse a los pueblos originarios como 'primitivos', 'carentes de identidad', etc., en contraste con los seres humanos 'civilizados', europeos opera la misma lógica ${ }^{49}$.

En un texto de 1972 titulado "La Teoría crítica, ayer y hoy», Horkheimer no sólo recordaba los orígenes del Instituto de Investigación Social y la contribución de Adorno a dicho proyecto intelectual sino que también apuntaba las dos ideas básicas de la Teoría crítica: por un lado, la idea de que, bajo el fascismo y el nacionalsocialismo, la sociedad se había hecho todavía más injusta y, por consiguiente,

47 Benjamin, W. Tesis sobre la Historia y otros fragmentos, Bogotá, Ediciones desde Abajo, 2013, p. 27.

48 Traverso, E. La pensée dispersée cit., p. 124.

49 García Corona, O. Una critica descolonial de la Escuela de Frankfurt cit., p. 220. 
la revolución era imprescindible y, por el otro, que sólo una sociedad justa permite la producción de un pensar verdadero ${ }^{50}$. Después de enumerar algunos errores de la visión de Marx, el autor de Dämmerung postuló lo siguiente: «nuestra Teoría crítica más moderna ya no defiende la revolución " ${ }^{51}$. La preocupación por el destino de la teología y de la religión tomaban el lugar otrora ocupado por la revolución. El texto concluía con un llamado a cuidarse de los «activistas» y remataba así: «el verdadero conservador se encuentra en muchos casos, no siempre, más cerca del verdadero revolucionario que del fascista, y el verdadero revolucionario más cerca del verdadero conservador que de lo que ahora llaman comunismo $»^{52}$. Curiosamente, en la época en que se publicaba ese texto, del otro lado del Atlántico estaba irrumpiendo una corriente teológica que asumía, sin cortapisas, el horizonte revolucionario: la Teología de la liberación. Expresión intelectual y espiritual del cristianismo de la liberación, e inspirada en la Revolución cubana de 1959, en el trabajo de las Comunidades Eclesiales de Base (CEB), en el testimonio profético de algunos cristianos (el cura guerrillero Camilo Torres Restrepo, el brasileño Henrique Pereira Neto, por ejemplo), la Teología de la liberación no sólo articuló la fe con lucha por la justicia social sino que además promovió una nueva cultura política que tuvo implicaciones sociopolíticas (no sólo en Latinoamérica) a lo largo del siglo xx y hasta nuestros días ${ }^{53}$. Sin renunciar a la perspectiva marxista, esta corriente teológica encarnó una intuición benjaminiana, la del mesianismo materialista. De ahí que, para Enrique Dussel, el fundador de la Filosofía de la liberación: «lo que intuyó Benjamin, la Teología de la Liberacion latinoamericana no sólo lo llevó a cabo sino que además lo reformuló, lo hizo política y lo hizo revolución» $»^{54}$.

\section{EL GIRO DESCOLONIAL DE LA FILOSOFÍA DE LA LIBERACIÓN}

Durante la década de los setenta del siglo pasado, en el espacio latinoamericano y caribeño habían surgido corrientes de pensamiento crítico que, amparándose de diferentes maneras del instrumental marxista, no sólo se oponían a los discursos académicos hegemónicos, sino que también proponían alternativas al

${ }^{50}$ Horkheimer, M. Sociedad en transición : estudios de filosofía social, Barcelona, Planeta, 1986, p. 58.

51 Ibidem, p. 59.

52 Ibidem, p. 70.

53 Martínez Andrade, L. Ecología y teología de la liberación. Crítica de la modernidad/ colonialidad, Barcelona, Heder, 2019.

54 Dussel, E. «Hacia la política y la economía de la vida», en Martínez andrade, L. (ed.), Las dudas de dios. Teología de la liberación, ecología y movimientos sociales, Santander, Otramérica, 2015, pp. 91-92. 
capitalismo $o^{55}$. Entre esas propuestas se encontraba la incipiente Filosofía de la liberación. Dicho movimiento filosófico comenzó con la descolonización epistemológica de la filosofía misma, pero desde un lugar de enunciación (locus enuntiationis) específico: la periferia del sistema-mundo capitalista. A partir de la polémica entre Augusto Salazar Bondy y Leopoldo Zea sobre la existencia de una filosofía propia de nuestra América, la filosofía de la liberación empezó a configurarse como una propuesta realmente descolonial. En diálogo con las discusiones planteadas por la teoría de la dependencia, la teología de la liberación, la pedagogía del oprimido y la sociología de la liberación, un grupo de jóvenes filósofos de diferentes universidades argentinas organizaron encuentros de manera regular para reflexionar sobre una cuestión en particular: ¿es posible una filosofía auténtica en nuestro continente subdesarrollado y oprimido? Teniendo como antecedente los encuentros en el poblado de Santa Rosa de Calamuchita en las sierras cordobesas y la I Semana Académica de la Universidad del Salvador, la filosofía de la liberación se configuró, a partir de la organización del I Congreso Nacional Argentino de Filosofía y de la II Semana Académica, en 1971. Dentro de los pioneros de este movimiento filosófico se puede mencionar el nombre de Enrique Dussel. Además, es importante mencionar que el teólogo brasileńo Hugo Assmann, antiguo estudiante de la Universidad de Frankfurt, no sólo acompañó la emergencia de este movimiento filosófico, sino que además insistió en la necesidad de clarificar el lenguaje de liberación ${ }^{56}$.

Por su parte, Enrique Dussel siempre ha insistido en el hecho de que la filosofía de la liberación, desde su origen, siempre mantuvo un diálogo constante con la Teoría crítica. Incluso, nos dice el filósofo argentino, durante la época de las dictaduras militares, la lectura de las obras de Herbert Marcuse (especialmente El hombre unidimensional) se combinaba con las de Frantz Fanon, de tal manera que «nuestra primera lectura de la teoría crítica no era ya eurocéntrica ${ }^{57}$. Para la filosofía de la liberación, la cuestión de la «materialidad», en el sentido de la corporalidad (Leiblichkeit) viviente, de la Escuela de Frankfurt, resultó de sumo interés, ya que tomaba en serio el sufrimiento de la víctima. Ahora bien, la filosofía de la liberación descolonizó el ángulo de la mirada al abordar la «negatividad material del colonialismo»:

La víctima no era ya para nosotros, como para Max Horkheimer, Jürgen Habermas o la tercera generación de la teoría crítica, solamente el obrero, el judío perseguido en Auschwitz, el ciudadano bajo el nazismo, la mujer o el mundo obrero ante la crisis del Estado de bienestar, sino que eran las víctimas de un sistema mundial (un world-system globalizado desde 1492) que incluía el sistema de la hacienda lati-

55 Roitman Rosenmann, M. Pensamiento sociológico y realidad nacionalen América Latina, México, Instituto de Estudios Educativos y Sindicales de América/SNTE, 2002; Cadet, J.J. Le Marxisme haïtien. Marxisme et anticolonialisme en Haïti (1946-1986), Paris, Delga, 2020.

56 Solís Bello Ortiz, N.L., ZúñIga, J., Galindo, M.S. y GonzÁlez, M.A. «Filosofía de la liberación», en Dussel, E., Mendieta, E. y Bohórquez, C. El pensamiento filosófico latinoamericano, del Caribe y «latino» (1300-2000), México, Siglo XXI, 2009, pp. 399-417.

57 Dussel, E. Filosofías del Sur. Descolonización y Transmodernidad, México, Akal, 2015, p. 52 . 
noamericana que explotaba al indio; el de la mita, otro sistema de trabajo obligatorio, pero aplicado a la extracción de planta en minas como la del Potosí (primera moneda mundial del capitalismo colonial); el de las plantaciones con esclavos africanos llevados a la América tropical; de las indias amancebadas con el conquistador, el de los niños educados en el cristianismo (dominación cultural por medio de una religión extraña), etcétera ${ }^{58}$.

Inspirado en la noción de exterioridad propuesta por el filósofo judío Emmanuel Lévinas, el filósofo argentino desarrolla, desde el no-ser, una crítica radicalmente descolonizadora de la Totalidad. Desde la década de los setenta, la filosofía de la liberación planteaba que la epifanía era la revelación del oprimido, del pobre, del otro y, en ese sentido, nunca es pura apariencia ni mero fenómeno, sino que mantiene una exterioridad metafísica. De ahí que el momento analéctico del movimiento dialéctico sea decisivo en la afirmación de la alteridad a través de una praxis de liberación. Por tanto, "el sujeto histórico, como fuerza poiética o productiva sobrante, es el origen de la afirmación de la alteridad, la manifestación interna de la exterioridad o la anticipación trascendental del nuevo sistema " ${ }^{59}$. La filosofía de la liberación asumió y buscó superar el método dialéctico negativo de la Teoría crítica, pero sin descuidar la «criticidad positiva de la utopía de la exterioridad política de los pueblos periféricos» ${ }^{60}$. De hecho, y en diálogo con la teología de la liberación, durante una serie de conferencias dictadas en el Instituto Pastoral Latinoamericano de Quito y en el Instituto de Liturgia de Medellín, Enrique Dussel ya se encontraba trabajando con temáticas, conceptos y categorías centrales de su filosofía de la liberación (analéctica; Praxis de dominación-Praxis de liberación; Totalidad-alteridad; Dentro-Fuera, entre otros). Publicadas en 1972 con el título Caminos de liberación latinoamericana, dichas conferencias no sólo abordaron la función crítica y liberadora de la fe sino que también subrayaron la dimensión ética del compromiso político:

la palabra liberación es muy concreta. Ha sido replanteada en esta época, por ejemplo, por el Frente de Liberación Nacional de Argelia. El Frente está inspirado, en gran parte, en Marx; y Marx a su vez se inspiró en Hegel; y Hegel sacó este término, entre otras fuentes, del Nuevo Testamento. El término «liberación» es propiamente cristiano; propiamente hebreo. En el Éxodo, Dios dice a Moisés: "Libéralo», es decir, sácalo del Egipto, sálvalos. En realidad, muchas veces se tradujo liberación por «redención», «salvación», etc., y estas palabras las conocemos. La liberación es una palabra estrictamente cristiana, supone una dialéctica, y esta dialéctica siempre parte de la opresión. Sí, se habla de liberación, pero no se sabe qué es lo que se deja detrás, entonces tampoco se tiene conciencia de la ruptura que significa y hacia dónde se dirige el proceso $^{61}$.

58 Ibidem, p. 55.

59 Dussel, E. Filosofía de la liberación, Bogotá, Nueva América, 1996, p. 162.

${ }^{60}$ Ibidem, p. 187.

${ }^{61}$ Dussel, E. Caminos de liberación latinoamericana, Buenos Aires, Latinoamérica Libros,

1972. 
En otro orden de ideas, la temática de la Conquista de América -y sus consecuencias ontológicas y estructurales- es central en la filosofía de la liberación. Sin embargo, a partir de la década de los noventa, el filósofo argentino -en diálogo con Aníbal Quijano (colonialidad del poder), Walter Mignolo (diferencia imperial/ diferencia colonial) e Immanuel Wallerstein (sistema-mundo moderno)- articuló la relación entre "el mito de la modernidad " ${ }^{62}$ (la emergencia del ego conquiro) y el desarrollo tanto del capitalismo como de la colonialidad del poder/saber ${ }^{63}$. Precisamente, uno de los aportes de la filosofía de la liberación al giro descolonial radica en su planteamiento sobre el «origen del mito de la modernidad», es decir, en el momento en que Europa se abre hacia el Atlántico configurando así una nueva ontología de dominación a escala planetaria ${ }^{64}$.

Para Eduardo Restrepo y Axel Rojas, la «herida colonial», esto es, la huella dejada por el dolor derivado de las experiencias padecidas en situaciones de marginalización, sometimiento, injustica, inferiorización y muerte, es central en los planteamientos de la filosofía de la liberación ${ }^{65}$. Sin embargo, más allá del «momento crítico negativo" de la Teoría crítica, la filosofía de la liberación propone un proyecto pluriverso transmoderno, es decir, una afirmación, como autovalorización, de los momentos culturales propios negados o simplemente despreciados que se encuentran en la exterioridad de la Modernidad, de tal suerte que los valores tradicionales ignorados o vilipendiados por la Modernidad sean el punto de arranque de una crítica interna ${ }^{66}$. Si Horkheimer y Adorno se detuvieron a examinar la tendencia a la autodestrucción permanente de la racionalidad instrumental del iluminismo y el aspecto destructor del progreso ${ }^{67}$, Dussel analiza la racionalidad colonialista propia del proyecto necrofílico de la modernidad/colonialidad realmente existente.

Frente a los discursos postmodernos y la ausencia cada vez más pronunciada de «materialidad» en las propuestas de los epígonos de la Escuela de Frankfurt, la filosofía de la liberación hace hincapié en la exterioridad:

categoría definida con mayor claridad conceptual que Horkheimer, Adorno o Marcuse por Levinas (y no adecuadamente comprendida por Derrida y considerada por Axel Honneth como «teológica» - no llegando a comprender la narrativa semita que permite una hermenéutica filosófica no habitual en la filosofía moderna

62 Dussel, E. 1492: el encubrimiento del Indio, México, CNCP, 1994.

${ }^{63}$ Véase el excelente trabajo de Ortega Reyna, J. Leer el Capital, Teorizar la Política: Contrapunteo de la obra de Enrique Dussel y Bolivar Echeverría en tres momentos, México, UNAM, 2018.

${ }^{64}$ Martínez Andrade, L. Religión sin redención. Contradicciones sociales y sueños despiertos en América Latina, Mexico, Taberna Libraria, 2012.

${ }_{65}$ Restrepo, E. y Rojas, A. Inflexión decolonial: fuentes, conceptos y cuestionamientos, Popayán, Instituto de Estudios Sociales y Culturales Pensar/Universidad del Cauca, 2010.

${ }^{66}$ Dussel, E. Filosofías del Sur cit., p. 293.

${ }^{67}$ Horkheimer, M. y Adorno, Th.W. Dialéctica del iluminismo, Buenos Aires, Sudamericana, 1969. 
occidental-), que permite situar mejor a las víctimas, que son sujetos sufrientes invisibles para el sistema vigente ${ }^{68}$.

Mientras que Max Horkheimer y Theodor Adorno terminaron instalándose cómodamente en el «Gran Hotel Abismo» y eludieron la traducción política de sus planteamientos teóricos, la filosofía de la liberación -cultivada por Enrique Dussel, principalmente- no sólo insiste en la necesidad de una praxis de liberación ${ }^{69}$ sino también en la importancia de descolonizar el pensamiento crítico. De manera que la reflexión en torno al momento analéctico de las víctimas, es decir, al proceso de ruptura en los que la insubordinación, la revuelta o la revolución se dan cita, es crucial para comprender el estado de rebelión de la comunidad mesiánica ${ }^{70}$.

\section{CONCLUSIÓN}

En su Fragmentos de Frankfurt. Ensayos sobre la Teoría crítica, el filósofo Stefan Gandler postula que "la Teoría crítica de la Escuela de Frankfurt ha muerto» ${ }^{71}$. Para este filósofo alemán avecindado desde hace ya varios años en México, el reconocimiento de este hecho es la primera condición para poder retomar el proyecto emancipatorio de la Teoría crítica. Después de revisar algunos planteamientos de Jürgen Habermas, de Axel Honneth y de Helmut Dubiel (a quienes el autor etiqueta como «herederos innobles de Horkheimer y Adorno»), Gandler advierte, por un lado, que la idea de continuidad de estos herederos innobles con el proyecto de la Teoría crítica no existe y, por el otro, que el proyecto de la Teoría crítica sí puede ser retomado si no se descarta el impulso autocrítico de la razón. De ahí que siga siendo necesario comprender la tendencia autodestructiva propia de nuestra formación social. Finalmente, Gandler reconoce los aportes de Bolívar Echeverria en el desarrollo de un marxismo crítico cercano al proyecto de la Teoría crítica ${ }^{72}$.

Efectivamente, como ya hemos mencionado, algunas de las propuestas críticas latinoamericanas han mantenido un diálogo constante con la Teoría crítica. Pensemos por ejemplo en la producción de Hugo Assmann y de Franz Hinkelammert. Figuras señeras de la Teología de la liberación, estos autores retomaron la teoría del fetichismo de Marx para comprender, desde una perspectiva interdisciplinaria, la

68 Ibidem, p. 68.

${ }^{69}$ Dussel, E. Politica de la liberación. Historia mundial y crítica, Madrid, Trotta, 2007; Politica de la liberación. Arquitectónica, Madrid, Trotta, 2009.

${ }^{70}$ Dussel, E. Pablo de Tarso en la filosofía politica actual y otros ensayos, México, San Pablo, 2012.

71 Gandler, S. Fragmentos de Frankfurt cit., p. 17.

72 Gandler, S. Marxismo critico en México: Adolfo Sánchez Vázquez y Bolivar Echeverria, México, FCE, 2007; El discreto encanto de la modernidad. Ideologías contemporáneas y su critica, México, Siglo XXI, 2013. 
dinámica sacrificial de la modernidad capitalista ${ }^{73}$. Incluso, en el campo de la teoría de conocimiento, al igual que Horkheimer y Adorno, estos teólogos realizaron una crítica materialista a los límites del positivismo y del idealismo. Como bien lo observó el recientemente finado filósofo boliviano Juan José Bautista, en Hinkelammert la discusión epistemológica es también una discusión política ${ }^{74}$.

Si bien no abordamos en este artículo el papel de Félix José Weil, creemos que las investigaciones de Jeanette Erazo Heufelder ${ }^{75}$, de Mario Rapoport ${ }^{76}$ y de Oscar García Corona son de gran valor ${ }^{77}$, pues permiten desconfinar su imagen a la de simple «mecenas» de la Escuela de Frankfurt (papel al que ha sido reducido por una historiografía eurocéntrica) y mostrar su importancia en la geopolítica del conocimiento. Notamos pues la importancia de seguir estudiando la genealogía de uno de los proyectos intelectuales más importantes del siglo xx. Aquel que fuera impulsado por un acaudalado argentino que se definía como un «bolchevique de salón».

En un momento de crisis civilizatoria en el que la sobrevivencia de la especie humana parece estar realmente en peligro, sigue siendo imprescindible llevar la lucha de clases a todos los campos del conocimiento ${ }^{78}$. Sin embargo, se impone también una ruptura con los marcos categoriales impuestos por el eurocentrismo y, en ese sentido, solamente una Teoría critica anticolonial-enriquecido por los aportes de los diversos feminismos no hegemónicos, del ecosocialismo, de las teologías de la liberación, de la ecología política, del marxismo heterodoxo y de la Critical race theory- podrá hacer frente a las «jugadas ideológicas» de los heraldos de esta modernidad/colonialidad realmente existente. Sí, una Teoría critica anticolonial que no tema encarar el antagonismo y, al mismo tiempo, devele los falsos dilemas planteados por la ideología liberal burguesa.

RECIBIDO: abril 2021; ACEPTADO: abril 2021

73 Da Silva Coelho, A. Capitalismo como religião. Walter Benjamin e os Teólogos da Libertação, São Paulo, Editora Recriar, 2021.

74 Bautista, J.J. ¿Qué significa pensar desde América Latina? Hacia una racionalidad transmoderna y postoccidental, Madrid, Akal, 2014, p. 138.

75 Erazo Heufelder, J. Der argentinische Krösus. Kleine Wirtschaftsgeschichte der Frankfurter Schule, Berlin, Berenberg Verlag, 2017.

${ }^{76}$ Rapoport, M. Bolchevique de salón. Vida de Félix J. Weil, el fundador argentino de la Escuela de Frankfurt, Buenos Aires, Debate, 2014.

77 García Corona, O. Una crítica descolonial de la Escuela de Frankfurt cit.

78 VV. AA., Pensar desde la Izquierda. Mapa del pensamiento critico para un tiempo de crisis, Madrid, Errata Naturae, 2012. 
